https://doi.org/10.15407/ujpe66.1.62

S.V. LYSOCHENKO, ${ }^{1,2}$ YU.S. ZHARKIKH, ${ }^{1}$ O.G. KUKHARENKO, ${ }^{1,2}$ O.V. TRETIAK, ${ }^{1}$ M.G. TOLMACHOV ${ }^{2}$

${ }^{1}$ Institute of High Technologies, Taras Shevchenko National University of Kyiv

(4G, Academician Glushkov Ave., Kyiv 03127, Ukraine; e-mail: lys@univ.kiev.ua)

2 Cooperation Center of Taras Shevchenko National University of Kyiv and Company "T.M.M." Ltd. (50A, Mashynobudivna Str., Kyiv 0306\%, Ukraine)

\title{
HALL STUDY OF CONDUCTIVE CHANNELS FORMED IN GERMANIUM BY BEAMS OF HIGH-ENERGY LIGHT IONS
}

\begin{abstract}
The implantation of the high-energy ions of $\mathrm{H}^{+}$or $\mathrm{He}^{+}$in germanium leads to the creation of buried conductive channels in its bulk with equal concentrations of acceptor centers. These centers are the structure defects of the crystal lattice which arise in the course of deceleration of high-energy particles. This method of introducing electrically active defects is similar to the doping of semiconductors by acceptor-type impurities. It has been established that the density of defects increases with the implantation dose till $\approx 5 \times 10^{15} \mathrm{~cm}^{-2}$. The further increase of the implantation dose does not affect the level of doping. In the range of applied doses $\left(10^{12}-\right.$ $\left.6 \times 10^{16}\right) \mathrm{cm}^{-2}$, the Hall mobility of holes in the formed conducting channels is practically independent of the implanted dose and is about (2-3) $\times 10^{4} \mathrm{~cm}^{2} / \mathrm{Vs}$ at $77 \mathrm{~K}$. The doping of the germanium by high-energy ions of $\mathrm{H}^{+}$or $\mathrm{He}^{+}$to obtain conducting regions with high hole mobility can be used in the microelectronics technology.

Keywords: Hall investigations, implantation, protons, $\alpha$-particles, buried conductive channels.
\end{abstract}

\section{Introduction}

The mobility value of free charge carriers imposes a physical limitation on the speed of microelectronic devices functioning. The speed of traditional siliconbased transistors has practically reached the limit $[1,2]$. In monocrystalline $\mathrm{Ge}$, the electron mobility is twice and the hole mobility is four times higher as compared with Si. Therefore, germanium is the more promising material for microelectronics now [3-6]. However, this mobility may change significantly due to interaction with defects in the real material. For example, specific defects are formed in germanium under irradiation with high-energy ions [7]. Such irradiation is used in the Proton Beam Writing (PBW) technology [8] to modify the physical properties of semiconductors [9]. In the present work, beams of protons and $\alpha$-particles are used to create hole conductive channels hidden under the irradiated surface of germanium samples [10]. The dependences

(C) S.V. LYSOCHENKO, YU.S. ZHARKIKH,

O.G. KUKHARENKO, O.V. TRETIAK,

M.G. TOLMACHOV, 2021 of the mobility and concentration of free charge carriers in the channels on the temperature and radiation doses are investigated. The features of transport phenomena and the formation of defects in these channels are considered. The main attention is paid to the study of the Hall data and their interpretation toward the origin of electrically active centers. The results are of current interest, because the studies conducted with the material and a technology of its modification, can be applied to create a new element base of microelectronics. This can also be used for investigations of physical processes in low-dimensional objects: buried two-dimensional channels, quantum wires and dots.

\section{Experimental Methods}

The samples were made of monocrystalline germanium of two types: Ge-doped with $\mathrm{Sb}(4 \times$ $\left.\times 10^{12} \mathrm{~cm}^{-3}\right)$ and Ge-doped with Sb $\left(2 \times 10^{14} \mathrm{~cm}^{-3}\right)$ and $\mathrm{Au}\left(4 \times 10^{14} \mathrm{~cm}^{-3}\right)$. The samples had parallelepiped shapes, one of the faces of which coincided with plane (111). The implantation of $\mathrm{H}^{+}$or $\mathrm{He}^{+}$ions with energy $E_{i}=1.5 \mathrm{MeV}$ was carried out through

ISSN 2071-0194. Ukr. J. Phys. 2021. Vol. 66, No. 1 
this face of the sample. Four indium contacts were fused on the lateral faces of the sample, two of which were used to supply an external electrical voltage, and another two were used to measure the Hall potential. The conducting channel between the currentcarrying contacts was created by the irradiation with an ion beam. The diameter of the focused beam was $40 \mu \mathrm{m}$. The irradiation was carried out at the movement of the sample, and the conductive channel $3 \mathrm{~mm}$ long and $0.44 \mathrm{~mm}$ wide was created. A detailed description of samples and the irradiation technique using the Kyiv ion microprobe are given in $[7,11]$. The implantation was carried out at room temperature of the samples holder. The energy of a focused beam was absorbed in a small pixel bulk, and, therefore, the effective dynamic annealing of the channel region occurred directly in the course of implantation.

The measurements were carried out while immersing the samples into liquid nitrogen or helium. The conductivity of samples after the irradiation was by orders of magnitude greater than before it and depended almost completely on the conductivity of channels after the implantation of light ions. The shunting effect of the sample bulk conductivity was negligible. It was cut off due to the presence of a $p-n$ junction between the $p$-channel and the $n$-type bulk (for samples doped with antimony only). For samples doped with $\mathrm{Sb}$ and $\mathrm{Au}$, the bulk conductivity was very low due to the compensation of $\mathrm{Sb}$ by deep $\mathrm{Au}$ levels.

\section{Results and Discussion}

\subsection{Dependence of channel conductivity and hole mobility as a function of irradiation doses}

The conductivity of a unit area of the channels $\sigma_{c}$ in samples irradiated by ions with the energy $E_{i}=$ $=1.5 \mathrm{MeV}$ at implantation doses $D_{i}$ within the range of $\left(10^{12}-6 \times 10^{16}\right) \mathrm{cm}^{-2}$ is shown in Fig. 1. Different shapes of the experimental points indicate the dose $D_{i}:(+)$ signs show the results obtained on different samples, where the complete $D_{i}$ was accumulated in a single dose irradiation. Points (o) were obtained by the measurements using the only one sample with a successive increase in the dose in the serial adding of protons. Experimental points $(\bullet)$ were obtained with the implantation of $\alpha$-particles.

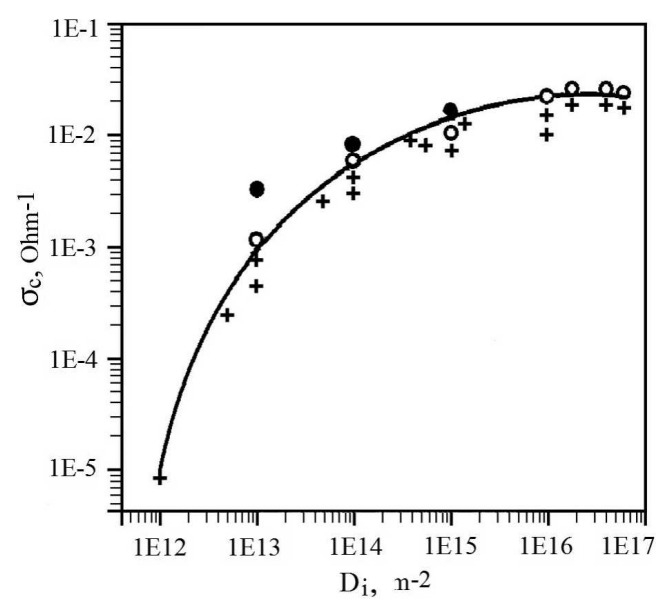

Fig. 1. Electric conductivity $\sigma_{c}$ of channels as a function of the implantation dose of ions $D_{i}$ at $77 \mathrm{~K}$. (+) - proton doses for a single irradiation of different samples, (o) - a set of proton doses for the serial irradiation of a single sample, $(\bullet)-$ irradiation with $\alpha$-particles

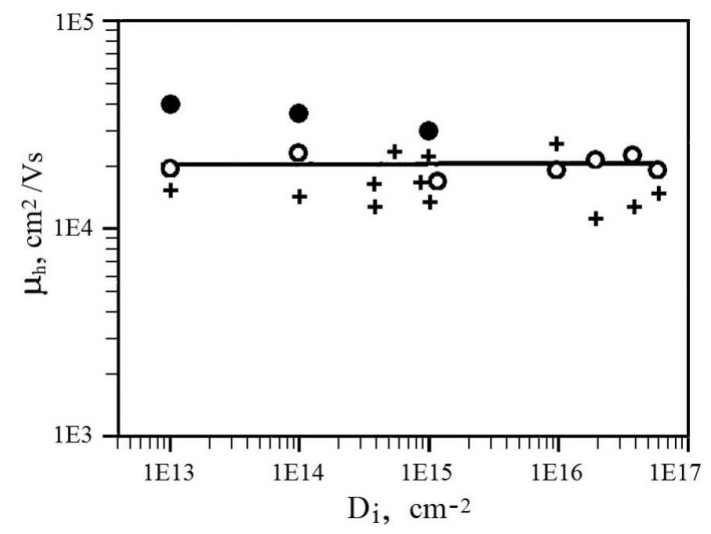

Fig. 2. Hall mobility $\mu_{h}$ of electric current carriers as a function of the implantation dose of ions $D_{i}$ at $77 \mathrm{~K}$. The measurements were performed with the samples used to measure the conductivity $\sigma_{c}$. The designations of experimental points correspond to those shown in Fig. 1

Figure 2 shows the dependence of the Hall mobility $\mu_{h}$ as a function of the dose $D_{i}$ measured at $77 \mathrm{~K}$. Based on the observed polarity of the Hall potential, it is found that the channels have $p$-type conductivity. Figure 2 shows that, as the dose of protons accumulates in one sample, the hole mobility remains almost unchanged (points (o) and their connecting line). The magnitude of this mobility is about $\approx(2-3) \times 10^{4} \mathrm{~cm}^{2} / \mathrm{Vs}$. The hole mobilities in channels of other samples $((+)$ points $)$ are scattered near this value of $\mu_{h}$. Thus, the hole mobility is practi- 


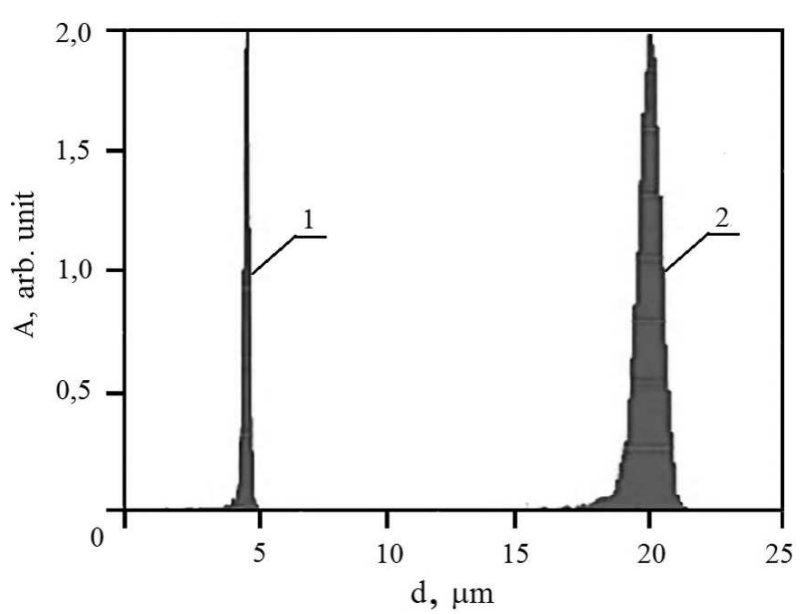

Fig. 3. Distribution of the concentration of implanted ions $A$ along the coordinate perpendicular to the sample surface. 1 $\alpha$-particles, 2 - protons. The ion energy is $E_{i}=1.5 \mathrm{MeV}$

cally independent of the proton dose $D_{i}$ accumulation method. In the channels obtained by the implantation of $\alpha$-particles (points $(\bullet)$, the mobility values also slightly change with increasing the dose $D_{i}$.

The dependence of the conductivity $\sigma_{c}$ of channels as a function of the temperature $T$ was measured within the interval of $T=(4.2-77) \mathrm{K}$. The implantation dose $D_{i}=10^{15} \mathrm{~cm}^{-2}$. Such a choice of $D_{i}$ was due to the fact that a dose increase above this value has little effect on the conductivity $\sigma_{c}$ (Fig. 1), which means that the maximum degree of germanium saturation with the formed electrically active centers is reached. It is found that the conductivity $\sigma_{c}$ depends exponentially on the temperature $T\left(\sigma_{c}=\sigma_{0} \exp \left(-E_{a} / k T\right)\right.$, where $E_{a}$ is the activation energy). The conductivity of channels formed by protons is characterized by one value of $E_{a}=$ $=E_{p}=1.6 \times 10^{-2} \mathrm{eV}$, whereas the conductivity of channels formed by $\alpha$-particles is characterized by two values of $E_{a}=E_{a 1}=5 \times 10^{-3} \mathrm{eV}$ and $E_{a}=$ $=E_{a 2}=2 \times 10^{-4} \mathrm{eV}$.

\subsection{Doping of samples with germanium structure defects}

The experimental data show that $\mu_{h}$ depends only weakly on the doses $\left(D_{i}\right)$ (Fig. 2), so the increase in the channel conductivity $\sigma_{c}$ by over three orders of magnitude from $\sigma_{c} \approx 10^{-5} \mathrm{Ohm}^{-1}$ to $\sigma_{c} \approx$ $\approx 10^{-2} \mathrm{Ohm}^{-1}$ (Fig. 1) must be due to the increase in the hole concentration. Consequently, the implantation of light ions causes the formation of acceptor- type centers. These centers are associated with defects formed in the course of embedding of protons or $\alpha$-particles [7, 10].

The greatest energy losses and formation of stable electrically active defects occur at the end of the stopping distance of particles. The distributions of particles implanted through (111) germanium face are calculated using the SRIM program [12] and shown in Fig. 3.

It can be seen that the regions of the greatest concentration of implanted ions are located below the surface at a distance $d$ much greater than the thickness of these regions $\omega$. Moreover, the region formed by $\alpha$-particles is at a depth four times smaller than that formed by protons ( $5 \mu$ and $20 \mu$, respectively). The thicknesses of these regions $\omega$ at the half-height of the distribution also differ by four times $(0.5 \mu$ and $2 \mu$, respectively). These differences are due to the peculiarities of energy loss on the stopping distance by particles whose masses differ by four times. It follows from the above that the conducting channels formed by the irradiation are hidden in the sample bulk.

Using the values of the activation energies of acceptor centers $E_{a}=E_{p}=1.6 \times 10^{-2} \mathrm{eV}$ or $E_{a}=E_{a 1}=$ $=5 \times 10^{-3} \mathrm{eV}$ given in Section 3.1, we can calculate the concentrations of defects $N_{i}=\Gamma / \omega \exp \left(E_{a} / k T\right)$ associated with such centers. The hole concentration per unit area of the channel was determined using the measured values of the conductivity $\sigma_{c}$ and mobility $\mu_{h}$. The obtained dependence of the concentration of electrically active defects $N_{i}$ in conducting channels as a function of the irradiation dose by protons or $\alpha$ particles is shown in Fig. 4. The designations of points in this figure are consistent with those used in Figs. 1 and 2 .

Figure 4 shows that the same doses at the ion implantation provide for approximately the same defect concentrations, regardless of the sample preparation method. The value of $N_{i}$ is practically independent of the doping of the initial germanium $(\mathrm{Sb}$ or $\mathrm{Sb}+\mathrm{Au}$ ) and of the type of implanted ions $\left(\mathrm{H}^{+}\right.$or $\left.\mathrm{He}^{+}\right)$. This indicates that the acceptor centers under consideration are not due to compositional defects and rather defects in the material structure [13].

Using the data presented in Fig. 4, we can calculate the density of protons required for the occurrence of one electrically active defect $Z_{p}=D_{i} / N_{p}$ (where $D_{i}$ is the dose of proton irradiation, and $N_{p}=N_{i} \omega$ is the number of electrically active de- 
fects per channel area unit). The resulting dependence $Z_{p}=\left(D_{i}\right)$ is shown in Fig. 4 with a dotted line. It can be seen that $Z_{p}$ value increases by almost than $10^{3}$ time with the dose of implanted protons $D_{i}$ from $10^{13}$ to $6 \times 10^{16} \mathrm{~cm}^{-2} \mathrm{~s}$. This may be due to a specificity of the hydrogen absorption. The germanium structure changes with increasing the implantation dose of $\mathrm{H}^{+}$ions. Works [14-16] indicate: i) low doses $\left(D_{i}<10^{13} \mathrm{~cm}^{-2}\right)$ cause such defects as multihydrogenated vacancies; ii) as the dose increases up to $D_{p} \approx 10^{15} \mathrm{~cm}^{-2}$, these defects store hydrogen and are transformed into extended internal surfaces, between which the nucleation of hydrogen occurs; iii) as a dose further increases up to $\left(D_{p}>10^{15} \mathrm{~cm}^{-2}\right)$, hydrogen continues to be accumulated in these pockets, increasing their bulk. Thus, with an increase in the implantation dose, an increasing part of hydrogen is absorbed and does not participate in the formation of electrically active centers. This is confirmed by the experimental data in Fig. 4. It can be seen that the dose $D_{p}$ increasing from $5 \times 10^{15} \mathrm{~cm}^{-2}$ up to $6 \times 10^{16} \mathrm{~cm}^{-2}$ do not change the density of electrically active centers $N_{i}$, but $Z_{p}$ continues to grow. In the same range of doses, the origination and propagation of microcracks occur [14-16].

At the implantation of $\alpha$-particles, the same bulk concentration of electrically active centers is generated, as in the case of protons implantation. This is testified by the data presented in Fig. 4 . Points $(\bullet)$ obtained by the $\alpha$-irradiation correspond to $N_{i}$ obtained at the same doses of the irradiation by protons. With the same bulk concentration of defects $N_{i}$, their number per unit area in the channels obtained by the implantation of $\alpha$-particles $N_{\alpha}=N_{i} \omega$ is 4 times less than in the channels doped with protons. This is due to the fact that the channels formed by $\alpha$ particles are 4 times thinner than the channels formed at the proton bombardment (Fig. 3). Consequently, the number of $\alpha$-particles required for the formation of one electrically active defect $\left(Z_{\alpha}=D_{i} / N_{a}\right)$ is 4 times greater than that at the implantation of protons $\left(Z_{\alpha}=4 \times Z_{p}\right)$ with the same irradiation doses $D_{i}$. This may be due to the fact that the coalescence of chemically passive and mobile helium occurs more efficiently than that of implanted hydrogen [14-16].

\subsection{Hole mobility in conducting channels}

As was noted in Section 3.1, the mobility $\mu_{h}$ shows small changes with an increase in the doping dose

ISSN 2071-0194. Ukr. J. Phys. 2021. Vol. 66, No. 1

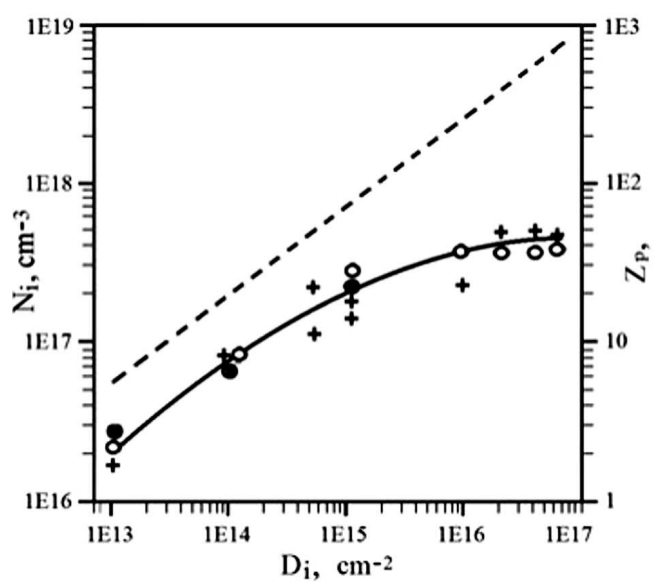

Fig. 4. Dependence of the concentration of electrically active defects $N_{i}$ as a function of the irradiation dose $D_{i}$ by protons or $\alpha$-particles. A designation of the points corresponds to that given in Figs. 1 and 2. The dotted curve shows the $Z_{p}\left(D_{i}\right)$ dependence

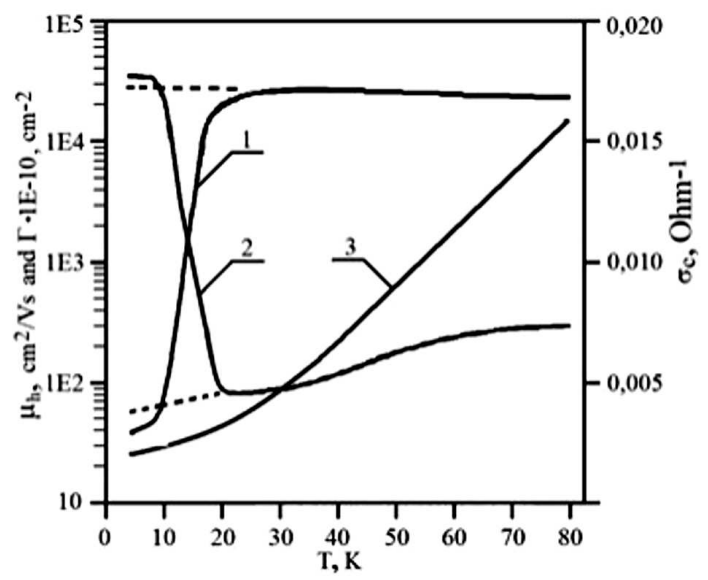

Fig. 5. Dependences of the mobility $\mu_{h}$ (curve 1), concentration $\Gamma_{h}$ (curve 2), and conductivity $\sigma_{c}$ (curve 3 ) of holes in a channel on the sample temperature $T$. Doping with $\alpha$-particles $D_{a}=10^{15} \mathrm{~cm}^{-2}, E_{i}=1.5 \mathrm{MeV}$

(Fig. 2) despite an increase in the density of defects and a complexity of their structure (Section 3.2). To establish the mechanism of scattering of holes, the dependence of their mobility on the sample temperature $\mu_{h}(T)$ was studied. The results are shown in Fig. 5 .

It can be seen that, at $T>25 \mathrm{~K}$, the mobility $\mu_{h}$ is practically independent of $T$. It is also found that the hole concentration $\Gamma$ and conductivity $\sigma_{c}$ are exponentially dependent on the temperature with the activation energy $E_{a 1}=5 \times 10^{-3} \mathrm{eV}$. The absence of a temperature effect on the mobility indicates that the 
scattering by charged centers and thermal phonons has no significant effect on the hole transport. This is a quite possible cause for the high hole mobility in the channels under study (Section 3.1).

At $T<25 \mathrm{~K}$, the mobility $\mu_{h}$ drops sharply with decreasing the temperature $T$ (curve 1 ), and the hole concentration $\Gamma$ increases by $10^{2}$ times (curve 2). At the same time, the conductivity $\sigma_{c}$ decreases exponentially with the activation energy $E_{a 2}=2 \times 10^{-4} \mathrm{eV}$ (curve 3). It is obvious that the concentration of free holes cannot increase with decreasing the temperature. Hence, the values of $\Gamma$ in Fig. 5 at $T<25 \mathrm{~K}$ do not correspond to the actual concentration of holes in the channel. The cause for this discrepancy is as follows. The concentration is determined on the basis of the $\Gamma=\sigma_{c} / e \mu_{h}$ ratio. This fact and the data in Fig. 5 show that the cause for a determined increase in $\Gamma$ is a decline in the measured Hall mobility $\mu_{h}$ at $T<25 \mathrm{~K}$. At the same time, since the increase in $\Gamma$ with decreasing the temperature $T$ is not consistent with the physical reality, a decrease in the real mobility cannot occur. In [17], it was shown that, in the samples filled with local inhomogeneities of the conductivity, the mobility measured by Hall methods is lower than the real mobility by conductivity. Thus, the identified features of the $\Gamma(T)$ and $\mu_{h}(T)$ dependences indicate that, as the temperature decreases, the channel conductivity $\sigma_{c}$ becomes more and more heterogeneous. This may be due to the twocomponent structure of the implanted region. The channel bulk is filled with a medium whose conductivity depends on the density of defects with the activation energy $E_{a 1}$. In this environment, there are many local regions whose conductivity is determined by defects with an activation energy $E_{a 2}$. As the temperature decreases from $T \approx 25 \mathrm{~K}$, the centers with the activation energy $E_{a 1}$ begin to freeze out, but the centers in the local regions continue to supply holes, because $E_{a 2} \ll E_{a 1}$. As a result, the heterogeneity of the channel conductivity increases.

At $T>25 \mathrm{~K}$, the centers of both types are activated, and, therefore, the channel heterogeneity is small. Under these conditions, the magnitude of the Hall mobility $\mu_{h}$ fits to the value of the transport mobility of holes. The dotted line in Fig. 5 shows the extrapolation of curve 1 to the region of low temperatures. Using the mobility values from this extrapolation, we calculate the $\Gamma(T)$ dependence. It is shown by a dotted line at the bottom of the figure. It can be seen that the dotted continuation is well in line with that part of curve 2, which was obtained at $T>25 \mathrm{~K}$. This suggests that, at $T<25 \mathrm{~K}$, the actual hole mobility is of the same magnitude as at $T<25 \mathrm{~K}$.

\section{Conclusions}

The irradiation of monocrystalline germanium with high-energy protons or $\alpha$-particles causes the formation of conducting channels. By the use of the Hall effect method, the $p$-type conductivity of these channels is established. Therefore, electrically active acceptortype centers are formed in germanium at the irradiation with light ions $\mathrm{H}^{+}$or $\mathrm{He}^{+}$. These centers are defects of the crystal lattice structure that arise in the course of deceleration of high-energy particles. The main results of the study of conducting channels obtained by the implantation of light ions with energy 1.5 MeV are as follows:

1. It is shown that, as the implantation dose $D_{i}$ increases from $10^{12} \mathrm{~cm}^{-2}$ up to $5 \times 10^{15} \mathrm{~cm}^{-2}$, the increase in the channel conductivity $\sigma_{c}$ is by over three orders of magnitude. A further increase in the dose $D_{i}$ up to $6 \times 10^{16} \mathrm{~cm}^{-2}$ do not lead to a change in the conductivity. The mobility $\mu_{h}$ of holes varies little throughout the entire dose range. The observed changes in the conductivity $\sigma_{c}$ are due to changes in the concentration of electrically active centers arising at the implantation of high-energy particles. It is found that, at the same implantation doses $D_{i}$, protons or $\alpha$-particles create the equal densities of electrically active defects $N_{i}$ per unit bulk of germanium.

2. Calculations of the distributions of the depths of implanted particles have shown that protons and $\alpha$ particles form conducting channels of different thicknesses $(2 \mu \mathrm{m}$ and $0.5 \mu \mathrm{m}$, respectively) and arise deeply beneath the irradiated surface $(20 \mu \mathrm{m}$ and $5 \mu \mathrm{m}$, respectively). With the same doses of implantation $D_{i}$, the concentration of electrically active defects per unit surface $N_{a}=N_{i} \times \omega$ is four times less in the thinner channels formed by $\alpha$-particles versus the channels implanted with protons.

3. It is found that increasing the implantation dose $D_{i}$ leads to increasing the number of implanted particles required for one electrically active center to arise. This, apparently, does not mean that the formation of such a center requires increasing the energy. This may indicate that, as the dose increases,

ISSN 2071-0194. Ukr. J. Phys. 2021. Vol. 66, No. 1 
the number of particles increases, the absorption of which does not lead to the formation of electrically active centers. For example, the coalescence of hydrogen or helium can allow these elements to be stored in microcracks.

4. The mobility $\mu_{h}$, concentration $\Gamma$, and conductivity $\sigma_{c}$ of the conducting channels formed by the implantation of $\alpha$-particles depend on the temperature $T$. It is found that electrically active centers of two types with different activation energies appear in the channel. As a result, at $T<25 \mathrm{~K}$, the channel conductivity becomes heterogeneous, and the measured values of the Hall mobility $\mu_{h}$ do not correspond to the real values of the transport mobility.

5 . It is found that, in the studied conducting channels, the holes have the high mobility $\mu_{h}=(2-4) \times$ $\times 10^{4} \mathrm{~cm}^{2} /$ Vs at $77 \mathrm{~K}$. Therefore, the doping of germanium with protons and $\alpha$-particles is a promising direction in the microelectronics development. The data considered show that the choice of the implantation dose depends on irradiation purposes. When doping germanium with light ions, the maximum conductivity $\sigma_{c}$ is achieved with the implantation dose of $D_{i}=5 \times 10^{15} \mathrm{~cm}^{-2}$. The implantation doses $D_{i}$ exceeding this value can be used in Smart Cut technology [18, 19].

1. C. Riddet, J.R. Watling, K.-H. Chan, E.H.C. Parker, T.E. Whall, D.R. Leadley, A. Asenov. Hole mobility in germanium as a function of substrate and channel orientation, strain, doping, and temperature. IEEE Trans. Electron Dev. 59 (7), 1878 (2012).

2. T. Hosoi, Y. Suzuki, T. Shimura, H. Watanabe. Mobility characterization of Ge-on-insulator metal-oxide-semiconductor field-effect transistors with striped Ge channels fabricated by lateral liquid-phase epitaxy. Appl. Phys. Lett. 105, 173502 (2014).

3. S. Dissanayake, Y.Zhao, S. Sugahara, M. Takenaka, S. Takagi. Channel direction, effective field, and temperature dependences of hole mobility in (110)- oriented Geon-insulator p-channel metal-oxide-semiconductor fieldeffect transistors fabricated by Ge condensation technique. J. Appl. Phys. 109, 033709 (2011).

4. Yu. X. Kang, J. Zhang, R. Takenaka, S. Takagi. Characterization of ultrathin-body germanium-on-insulator (GeOI) structures and MOSFETs on flipped Smart-Cut ${ }^{\mathrm{TM}}$ GeOI substrates. Solid-State Electron. B 115, 120 (2016).

5. Z. Zheng, X. Yu, M. Xie, R. Cheng, R. Zhang, Y. Zhao. Demonstration of ultra-thin buried oxide germanium-oninsulator MOSFETs by direct wafer bonding and polishing techniques. Appl. Phys. Lett. 109, 023503 (2016).
6. B. Yurong, Xu. Jingping, L. Lu, F. Minmin. Simulation of electrical characteristics and structural optimization for small-scaled dual-gate GeOI MOSFET with high-k gate dielectric. Chinese J. of Semiconductors 35 (9), 094002-1 (2014).

7. Yu.S. Zharkikh, S.V. Lysochenko, O.G. Kukharenko, O.V. Tretiak. Conductive channels formed in germanium by high-energy protons and alpha particles. Nucl. Instr. Meth. Phys. Rev. B 441, 63 (2019).

8. F. Watt, M. B. Breese, A.A. Bettiol, J.A. van Kan. Proton beam writing. Mater. Today. 10 (6), 20 (2007).

9. V.V. Kozlovski, V.A. Kozlov, V.N. Lomasov. Modification of semiconductors by proton beams. Phys. Tech. Semiconductors 34 (2), 129 (2000).

10. Yu S. Zharkikh, S.V. Lysochenko, S.A. Lebed, O.G. Kukharenko, N.G. Tolmachev, O.V. Tretiak. Formation of hidden conductive channels under bombardment of germanium by high energy protons. Techn. Phys. Lett. 39 (10), 851 (2013).

11. S. Lebed, M. Tolmachov, O. Kukharenko, O. Veselov. Recent status of the Kiev nuclear probe. Nucl. Instrum. Methods Phys. Res. Section B 267 (12-13), 2013 (2009).

12. J.F. Ziegler, M.D. Ziegler, J.P. Biersack. SRIM: The Stopping and Range of Ions in Matter (Cadence Design Systems, 2008) [ISBN: 9780965420716, 096542071X].

13. V.A. Kozlov, V.V. Kozlovski. Doping of semiconductors using radiation defects produced by irradiation with pronons and alpha particules. Semiconductors 35 (7), 735 (2001).

14. P.F.P. Fichtner, J.R. Kaschny, A. Kling, H. Trinkaus, R.A. Yankov, A. Mucklich, W. Skorupa, F.C. Zawislak, L. Amaral, M.F. da Silva, J.C. Soares. Nucleation and growth of platelet bubble structures in He implanted silicon. Nucl. Instrum. Methods Phys. Res. B 136-138, 460 (1998).

15. J.M. Zahler, A. Fontcuberta, I. Morral, M.J. Griggs, H.A. Atwater, Y.J. Chabal. Role of hydrogen in hydrogeninduced layer exfoliation of germanium. Phys. Rev. B 75, 035309 (2007).

16. I.P. Ferain, K.Y. Byun, C.A. Colinge, S. Brightup, M.S. Goorsky. Low temperature exfoliation process in hydrogen-implanted germanium layers. J. Appl. Phys. 107, 054315 (2010).

17. L.N. Abessonova, V.N. Dobrovolskii, Y.S. Zharkikh, O.S. Frolov, A.Y. Shik. On the interpretation of Hall measurements in inhomogeneous semiconductors. Phys. Tech. Semicond. 10 (2), 406 (1976).

18. F. Letertre, C. Deguet, C. Richtarch, B. Faure, J.M. Hartmann, F. Chieu, A. Beaumont, J. Dechamp, C. Morales, F. Allibert, P. Perreau, S. Pocas, S. Personnic, C. LagaheBlanchard, B. Ghyselen, Y.M. Le Vaillant, Jalaguier, N. Kernevez, C. Mazure. Germanium-On-Insulator (GeOI) structure realized by the Smart $\mathrm{Cut}^{\mathrm{TM}}$ technology. SolidState Electronics 809, B4.4 (2011).

19. Chr. Maleville, C. Mazure. Smart-cut technology: From $300 \mathrm{~mm}$ ultrathin SOI production to advanced engineered substrates. Solid-State Electron. 48 (6), 1055 (2004).

Received 09.10.19 
С.В. Лисоченко, Ю.С. Жарких,

О.Г. Кухаренко, О.В. Третяк, М.Г. Толмачов

ХОЛІВСЬКІ ДОСЛІДЖЕННЯ

ПРОВІДНИХ КАНАЛІВ, СФОРМОВАНИХ

У ГЕРМАНІЇ ПУЧКАМИ ЛЕГКИХ

IОНІВ ВИСОКИХ ЕНЕРГІЙ

Імплантація високоенергетичних іонів $\mathrm{H}^{+}$або $\mathrm{He}^{+}$в германій приводить до створення заглиблених в об'єм провідних каналів з однаковими концентраціями акцепторних центрів. Такі центри є дефектами структури кристалічної гратки, які виникають у процесі уповільнення високоенергетичних іонів. Такий спосіб введення електрично активних дефектів $є$ аналогічним процесу легування напівпровідників домішками акцепторного типу. Встановлено, що концентрація дефектів збільшується зі збільшенням дози імплантації до $\approx 5 \cdot 10^{15} \mathrm{~cm}^{-2}$. Подальше збільшення дози імплантації не впливає на рівень легування. У діапазоні застосованих доз $\left(10^{12}-6 \cdot 10^{16}\right) \mathrm{cм}^{-2}$ холівська рухливість дірок в утворених провідних каналах практично не залежить від дози імплантації і становить приблизно $(2-3) \cdot 10^{4} \mathrm{~cm}^{2} \mathrm{~B}^{-1} \mathrm{c}^{-1}$ при $77 \mathrm{~K}$. Легування германію легкими іонами $\mathrm{H}^{+}$або $\mathrm{He}^{+}$високих енергій для отримання провідних областей з високою рухливістю дірок може бути використане в технологіях мікроелектроніки.

Ключові слова: холівські дослідження, імплантація, протони, $\alpha$-частинки, заглиблені провідні канали. 